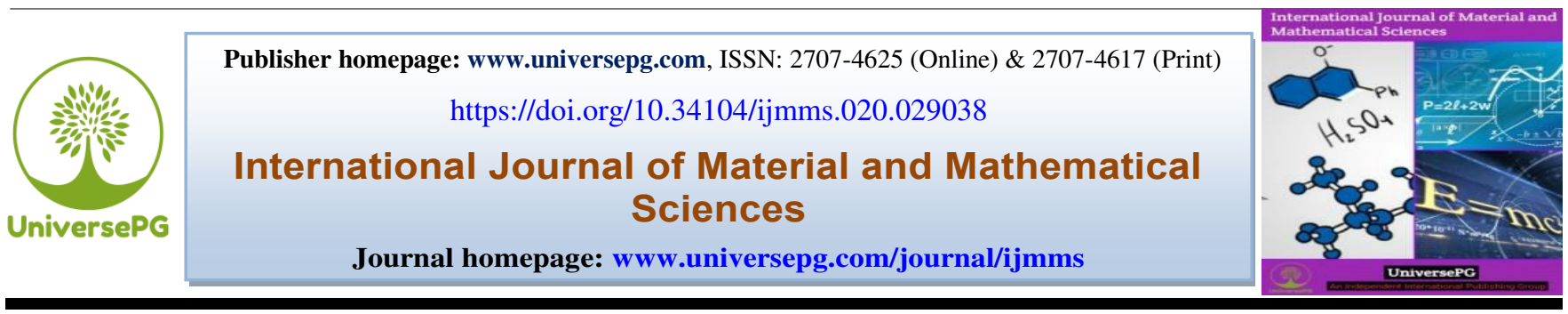

\title{
MHD Free Convective Heat Transfer in a Triangular Enclosure Filled with Copper-Water Nanofluid
}

\author{
Tarikul Islam $^{1 *}$, Nahida Akter ${ }^{2}$, and Nusrat Jahan ${ }^{3}$ \\ ${ }^{1 \& 2}$ Department of Mathematics, Bangabandhu Sheikh Mujibur Rahman Science and Technology University, Gopalganj, \\ Bangladesh; ${ }^{3}$ Department of Science and Humanity, Bangladesh Army International University of Science and Technology, \\ Cumilla, Bangladesh. \\ *Correspondence: tarikulamath@gmail.com
}

\begin{abstract}
Two-dimensional time independent free convective flow and temperature flow into a right-angled triangle shape cavity charged by $\mathrm{Cu}-\mathrm{H}_{2} \mathrm{O}$ nanofluid has been performed. The horizontal side of the enclosure is warmed uniformly $T=T_{h}$ whilst the standing wall is cooled at low temperature $T=T_{c}$ and hypotenuse of the triangular is insulated. The dimensionless non-linear governing PDEs have been solved numerically employing the robust PDE solver the Galerkin weighted residual finite element technique. An excellent agreement is founded between the previous, and present studies. The outcomes are displayed through streamline contours, isotherm contours, and local and average Nusselt number for buoyancy-driven parameter Rayleigh number, Hartmann number, and nanoparticles volume fraction. The outcomes show that the temperature flow value significantly changes for the increases of Rayleigh number, Hartmann number, and nanoparticles volume fraction. Average Nusselt number is increased for the composition of nanoparticles whereas diminishes with the increase of Hartmann number.
\end{abstract}

Keywords: Nanoparticles, MHD, Heat transfer, Finite element method, Free convection, and Triangular cavity.

\section{INTRODUCTION:}

Temperature transfer and fluid flow of nanofluids into the triangle shape enclosure have a wide applications in numerous industrial and engineering systems like heat exchangers, fire prevention, solar collectors, home ventilation systems, and refrigeration units etc. $\mathrm{Cu}$-water, $\mathrm{Al}_{2} \mathrm{O}_{3}$-water, and $\mathrm{TiO}_{2}$-water are very common nanofluids. These nanofluids are used widely for the augmentation of temperature transfer. Enhancement of warmed-up conductivity into nanofluids was studied by Choi and Eastman (1995). Manca et al. (2010) performed heat transfer in nanofluids. Influence of external magnetic field on natural convective flow into rectangle shape enclosure UniversePG I www.universepg.com using warmed up and cooled neighbor walls was investigated by Ece and Buyuk (2006). Convective temperature disposal within a cavity heated partially was performed by Ozotop and Abu-Nada (2008). Free convective temperature flow value into nanofluids within an inclined was performed by Ghasemi and Aminossadati (2009). Impact of inclined angle using copper-water nanofluids within an enclosure was investigated Abu-Nada et al. (2009). Varol et al. (2007) investigated free convectional flow within a triangle shape cavity using isothermal heater. Numerical computations of FEM on convectional temperature flow into nanofluids within a rectangle shape enclosure was performed by Rahman et al. 
(2009). FEM numerical computations on free convection into nanofluids within a triangle shape cavity in account of both uniform and non-uniform warmed boundary condition was investigated by Basak et al. (2008). A comprehensive review on convectional flow was researched Kamiyo et al. (2010). Aydin and Yesiloz (2011) investigated usual convectional flow into a quadrantal enclosure using warmed and cooled neighbor walls.

Magnetic field which creates an external force on the thermal and energy systems that highly attack the liquid flow and temperature flowing. Sheikholeslami et al. (2014) researched about $\mathrm{CuO}$-water nanofluid effect on convectional flow taking into account Lorentz force in flow domain. Computational study using $\mathrm{Al}_{2} \mathrm{O}_{3}$-water nanofluids on natural convectional flow was investigated by Rashmi et al. (2011). Bhardwaj and Dalal (2013) investigated convectional temperature flow as well as entropy generation into a right-angled shape triangle cavity. Natural convectional flow into a nanofluid using horizontal warmed plate was studied by Arani et al. (2011). Combined convectional flow and temperature flow characteristics into lid-driven square enclosure using heated blocks was investigated by Boulahia et al. (2016). Magneto hydro dynamics free convectional temperature transfer into nanofluid within isosceles triangle shape cavity was performed by Rahman et al. (2016). Convectional temperature flow into nanofluid within a triangular shape cavity was performed by Uddin et al. (2018).

From the literature review, the principle intention is to investigate the temperature flow and fluid flow within a right-angled triangle shape cavity charged by copper-water nanofluid. The impact of Rayleigh number, volume fraction of nanoparticles and Hartmann number are performed numerically and discussed them from physical point of view.

\section{FORMULATION OF PROBLEM:}

\section{Physical Model:}

For present study, schematic spectacle for right-angled triangular enclosure has been presented in Fig 1. The length of vertical and horizontal wall of the enclosure is $L$. The vertical side of enclosure is heated at a low heat $T=T_{c}$, whilst its horizontal side is heated at temperature $T=T_{h},\left(T_{c}<T_{h}\right)$, and the inclined wall is insulated. The enclosure charged as water $\left(\mathrm{H}_{2} \mathrm{O}\right)$ for base fluid and copper $(\mathrm{Cu})$ for nanoparticles. The gravitational acceleration $g$ acts in downward approach towards $y$-axis and a uniformly external magnetic field including power $\left(B_{0}\right)$ is also imposed towards horizontal approach. The nanofluid is calculated as incompressible and laminar. Two dimensional time independent flow is processed for current study (Islam et al., 2020). The characteristics of nanoparticles and base fluid is given in Table 1. All solid boundaries are announced as no slip walls.

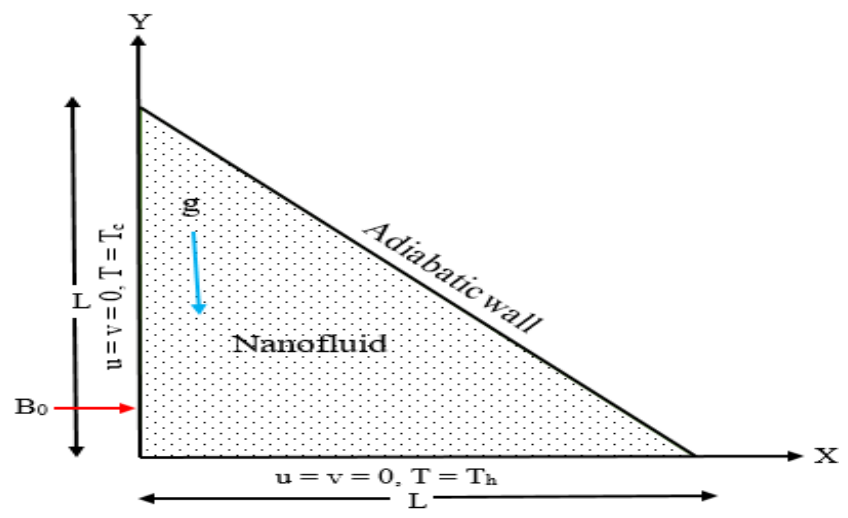

Fig 1: Schematic spectacle of right-angled triangular enclosure.

Table 1: Thermo-physical characteristics of the base fluid and solid particles.

\begin{tabular}{|c|c|c|}
\hline $\begin{array}{c}\text { Physical } \\
\text { properties }\end{array}$ & Copper $(\mathrm{Cu})$ & Water $\left(\mathrm{H}_{2} \mathrm{O}\right)$ \\
\hline$c_{p}\left[\mathrm{Jkg}^{-1} \mathrm{~K}^{-1}\right]$ & 385 & 4179 \\
\hline$\rho\left[\mathrm{kgm}^{-3}\right]$ & 8933 & 997.1 \\
\hline$k\left[\mathrm{Wm}^{-1} \mathrm{~K}^{-1}\right]$ & 400 & 0.613 \\
\hline$\mu\left[\mathrm{kgm}^{-1} s^{-1}\right]$ & - & 0.001003 \\
\hline$\beta \times 10^{-5}\left[\mathrm{~K}^{-1}\right]$ & 1.67 & 21 \\
\hline$\sigma\left[\mathrm{Sm}^{-1}\right]$ & $5.96 \times 10^{7}$ & $5.5 \times 10^{-6}$ \\
\hline $\operatorname{Pr}$ & - & 6.8377 \\
\hline
\end{tabular}

\section{Mathematical Model:}

The governing equations under aforementioned assumption in Cartesian co-ordinate system as follows: 
$\frac{\partial u}{\partial x}+\frac{\partial v}{\partial y}=0$

$u \frac{\partial u}{\partial x}+v \frac{\partial u}{\partial y}=-\frac{1}{\rho_{n f}} \frac{\partial p}{\partial x}+\frac{\mu_{n f}}{\rho_{n f}}\left(\frac{\partial^{2} u}{\partial x^{2}}+\frac{\partial^{2} u}{\partial y^{2}}\right)$

$\rho_{n f}\left(u \frac{\partial v}{\partial x}+v \frac{\partial v}{\partial y}\right)=-\frac{\partial p}{\partial y}+\mu_{n f}\left(\frac{\partial^{2} v}{\partial^{2} x}+\frac{\partial^{2} v}{\partial^{2} y}\right)$

$+(\rho \beta)_{n f} \mathrm{~g}\left(T-T_{c}\right)-\sigma B_{0}{ }^{2} v$

$u \frac{\partial T}{\partial x}+v \frac{\partial T}{\partial y}=\alpha_{n f}\left(\frac{\partial^{2} T}{\partial^{2} x}+\frac{\partial^{2} T}{\partial^{2} y}\right)$

\section{Boundary conditions:}

on horizontal wall: $u=0, v=0, T=T_{h}$

on perpendicular wall: $u=0, v=0, T=T_{c}$

on inclined wall: $u=0, v=0, \frac{\partial T}{\partial x}=0$

\section{Dimensional Analysis:}

The dimensionless variables are listed below:

$$
\begin{aligned}
& X=\frac{x}{L}, U=\frac{u L}{\alpha_{b f}}, \theta=\frac{T-T_{c}}{T_{h}-T_{c}}, P=\frac{p L^{2}}{\rho_{n f} \alpha_{b f}^{2}} \\
& Y=\frac{y}{L}, V=\frac{v L}{\alpha_{b f}}, H a=B_{o} L \sqrt{\sigma_{b f} / \mu_{b f}}, \\
& \operatorname{Pr}=\frac{v_{b f}}{\alpha_{b f}}, R a=\frac{g \beta_{b f}\left(T_{h}-T_{c}\right) L^{3}}{v_{b f} \alpha_{b f}},
\end{aligned}
$$

Using the dimensionless variables in equations (1)-(4), the non-dimensional equations are:

$\frac{\partial U}{\partial X}+\frac{\partial U}{\partial Y}=0$

$U \frac{\partial U}{\partial X}+V \frac{\partial U}{\partial Y}=-\frac{\rho_{b f}}{\rho_{n f}} \frac{\partial P}{\partial X}+\operatorname{Pr}\left(\frac{\rho_{b f}}{\rho_{n f}}\right)\left(\frac{\partial^{2} U}{\partial X^{2}}+\frac{\partial^{2} U}{\partial Y^{2}}\right)$

$U \frac{\partial V}{\partial X}+V \frac{\partial V}{\partial Y}=-\frac{\rho_{b f}}{\rho_{n f}} \frac{\partial P}{\partial Y}+\operatorname{Pr}\left(\frac{\rho_{b f}}{\rho_{n f}}\right)\left(\frac{\partial^{2} V}{\partial^{2} X}+\frac{\partial^{2} V}{\partial^{2} Y}\right)$

$+\frac{(\rho \beta)_{n f}}{\rho_{n f} \beta_{b f}} \operatorname{RaPr} \theta-\frac{\rho_{b f}}{\rho_{n f}} \frac{\sigma_{n f}}{\sigma_{b f}} H a^{2} \operatorname{Pr} V$

$U \frac{\partial \theta}{\partial X}+V \frac{\partial \theta}{\partial Y}=\left(\frac{\alpha_{n f}}{\alpha_{b f}}\right)\left(\frac{\partial^{2} \theta}{\partial^{2} X}+\frac{\partial^{2} \theta}{\partial^{2} Y}\right)$

Dimensionless boundary conditions are:

on horizontal wall: $U=0, V=0, \theta=1$ on perpendicular wall: $U=0, V=0, \theta=0$

on inclined wall: $U=0, V=0, \frac{\partial \theta}{\partial X}=0$

Local Nusselt number is defined towards horizontal hot wall of the cavity as

$N u_{L}=\frac{L q_{w}}{k_{b f}\left(T_{h}-T_{c}\right)}$, where $q_{w}=-k_{n f}\left(\frac{\partial T}{\partial x}\right)_{x=0}$

Average Nusselt number on horizontal hot side can be calculated:

$N u_{a v}=-\left(\frac{k_{n f}}{k_{b f}}\right) \int_{0}^{1} \frac{\partial \theta}{\partial X} d Y$

\section{COMPUTATIONAL PROCEDURE:}

Governing dimensionless equations (7)-(10) including boundary conditions (11a)-(11c) are concluded numerically by using finite element technique of Galerkin weighted residual type that is very powerful tool to solve these kinds of nonlinear equations. This method is expressly explained by Zienkiewicz and Taylor (1991). The computational procedure for the present problem is accomplished using excellent PDEs solver Comsol Multi physics. For grid independent solution, a comprehensive mesh testing technique is calculated to guarantee the numerical solution when $R a=10^{4}$.

The subsequent five variant distinct grids designated as normal, fine, finer, extra fine, and extremely fine including of $1187,1757,5067,13333$ and 16773 elements in resolution field respectively. Average Nusselt number is considered for checking the grid delicacy for the aforementioned elements. Table 2 displays that average Nusselt number for 13333 elements exhibits less difference form compared to other elements. Consequently, grid size of 13333 elements is considered of the grid independent solution.

Table 2: Susceptibility of grid for $\mathrm{Cu}-\mathrm{H}_{2} \mathrm{O}$ nanofluid when $R a=10^{4}$.

\begin{tabular}{|c|c|c|c|c|c|}
\hline Nodes & 644 & 938 & 2666 & 6914 & 8643 \\
\hline Elements & 1187 & 1757 & 5067 & 13333 & 16773 \\
\hline$N u_{a v}$ & 4.2766 & 4.2776 & 4.2856 & 4.2916 & 4.2916 \\
\hline
\end{tabular}


We have compared our outcomes (bottom row) using streamline contours (left column) and isotherm contours (right column) along Yesiloz et al. (2013) (top row) for checking the validity of the present numerical scheme when $R a=10^{4}$ in Fig 2. The results show a strong agreement and gives us the confidence for using the current numerical scheme.

\section{Code Validation:}
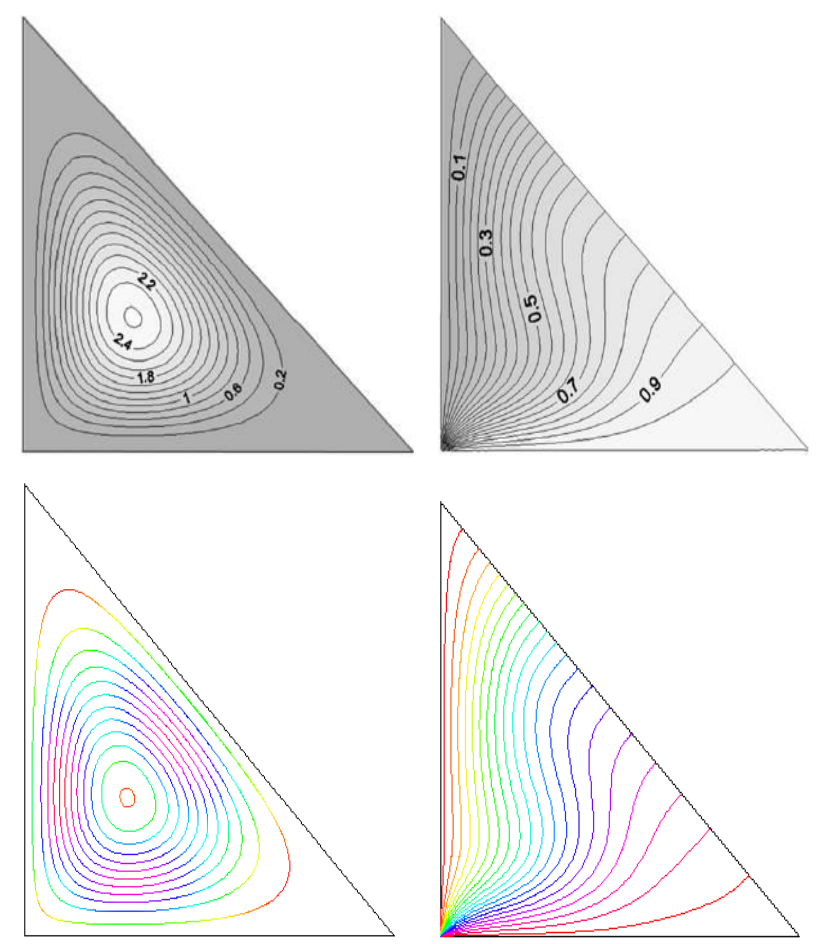

Fig 2: Comparison between present study (bottom) and Aydin and Yesiloz (2011) (top) when $R a=10^{4}$.

\section{RESULT AND DISCUSSION:}

The convectional temperature and fluid flow using $\mathrm{Cu}-\mathrm{H}_{2} \mathrm{O}$ nanofluids within right angled triangle shape enclosure is researched numerically by Galerkin weighted residual finite element method.

The numerical results is presented and discussed for the parameters like the Rayleigh number ( $R a)$, Hartmann number ( $\mathrm{Ha}$ ) and the volume fraction by the nanoparticles $(\phi)$ using isotherms contours streamline contours and average Nusselt number.

\section{Impact of Rayleigh Number:}

Fig 3(a) demonstrates impact for Rayleigh number $\left(R a=10^{4}, 10^{5}, 10^{6}, 10^{7}\right)$ on streamline contours when $\phi=0.04, H a=10$. This figures illustrate that for low $R a,\left(R a=10^{4}\right)$, the streamlines are not comprehendsively affected by the particles of the nanofluid though horizontal wall is heated uniform. This is a good indication of strong conduction. As Rayleigh number increases $R a\left(\geq 10^{5}\right)$ fluid within the enclosure becomes more decomposed on account of temperature flow in that region quickly by convection. In addition, for the increase of $R a$, compactness of streamline contours as well vortex strength within cavity enhances on account of predominance of free convection. Hence, convection is the dominant type of temperature flow for higher $R a$. Fig 3(b) depicts the impact for Rayleigh number $\left(R a=10^{4}, 10^{5}, 10^{6}, 10^{7}\right)$ on isotherm contours when $\phi=0.04, H a=10$. This figure displays that the streamlines are not superfluously impact within cavity for low Rayleigh number which announces that conduction is the original mode of temperature flow. As Rayleigh number improves $\left(R a \geq 10^{5}\right)$, denseness of the isothermal contours at the center within cavity decreases. This figure also show that the isothermal contours get close to each other and also collateral to each other and closely packed neighbor horizontal warmed as well as perpendicular cold walls as a result of the dominance of the free convection. Consequently, the temperature transfer value is enhanced with the increase of Rayleigh number $(R a)$ caused by the potential convection mode.

\section{Impact of Hartmann Number}

Fig 4(a) depicts the results of the Hartmann number (H $a=0,10,50,100)$ on streamline contours when $\phi=0.04$, and $R a=10^{5}$. Fig 4(a) shows that the flow circulations are nearly total place within the enclosure as well as develop a clockwise rotational chamber for low Hartmann number $(\mathrm{Ha}=0)$. 

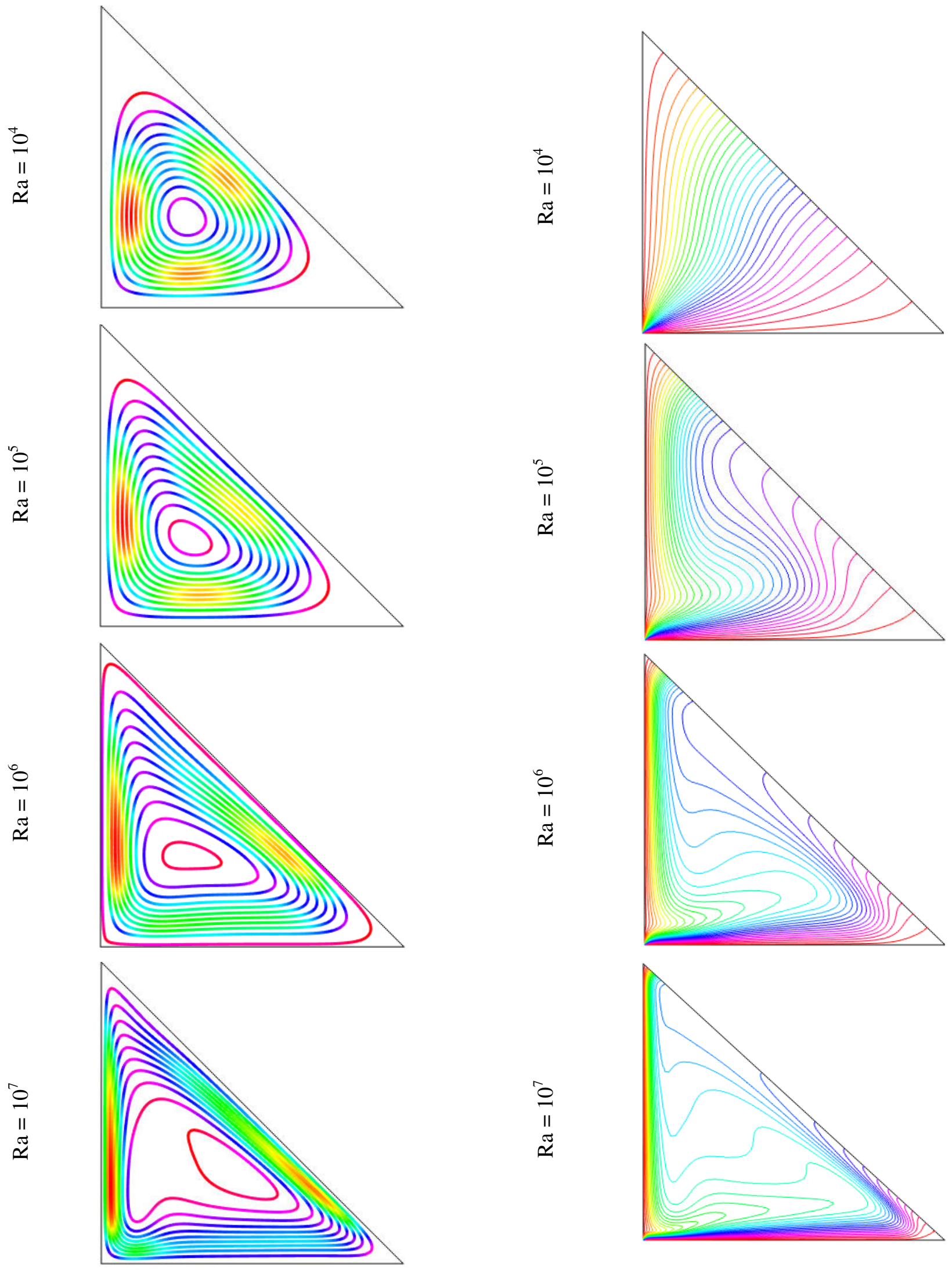

Fig 3(a): Results of $R a$ on streamlines when $\phi=0.04$, and $H a=10$.

Fig 3(b): Results of $R a$ on isotherms when $\phi=0.04$ and $H a=10$. 

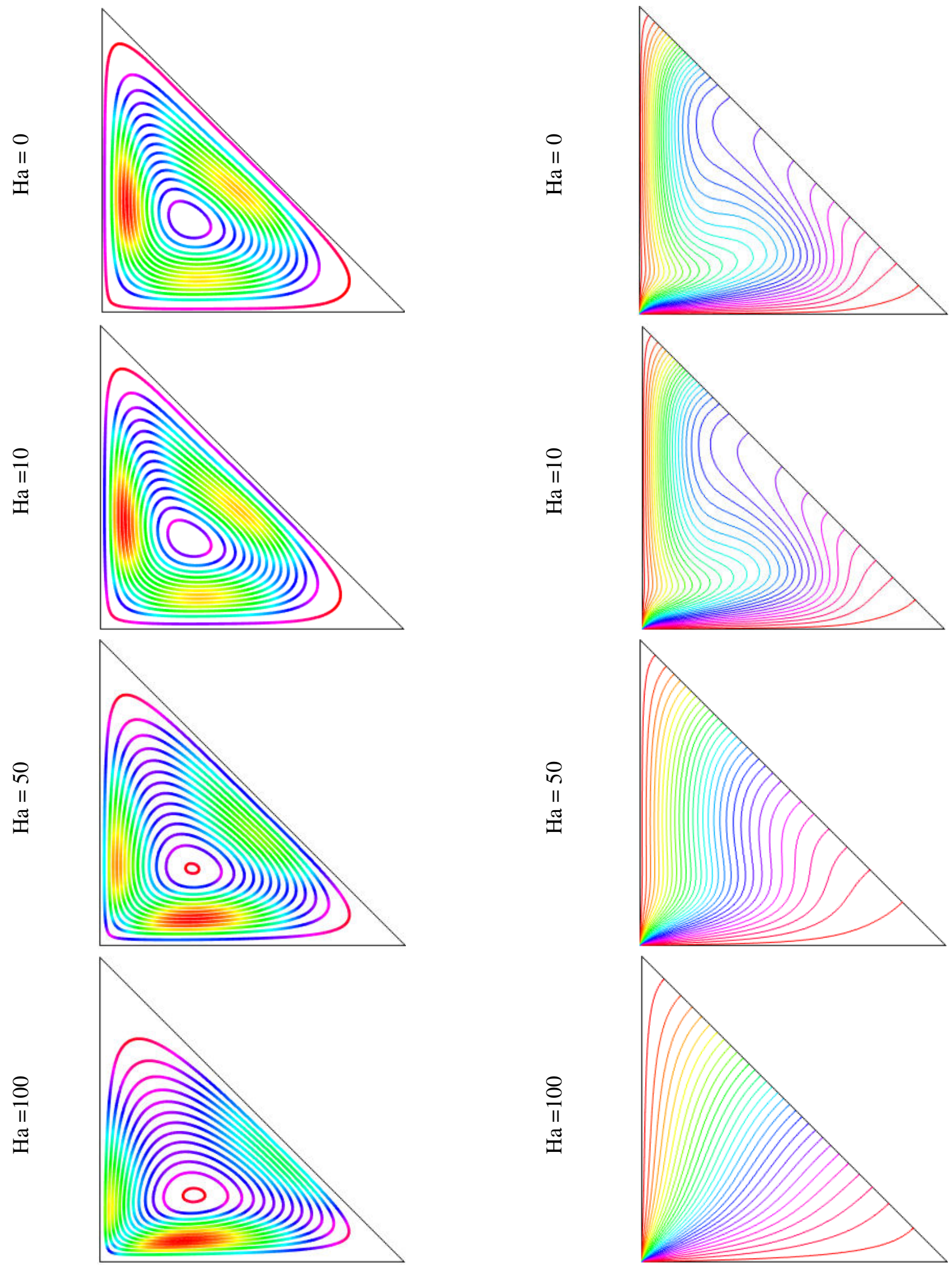

Fig 4(a): Effect of $H a$ on streamlines when $\phi=0.04$, and $R a=10^{5}$.

Fig 4(b): Effect of $H a$ on isotherms when $\phi=0.04$, and $R a=10^{5}$. 


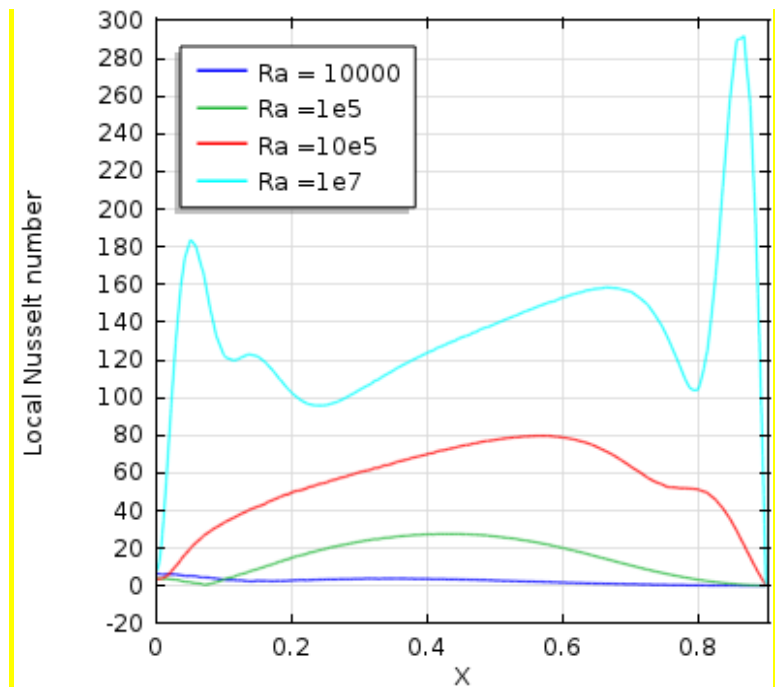

(a)

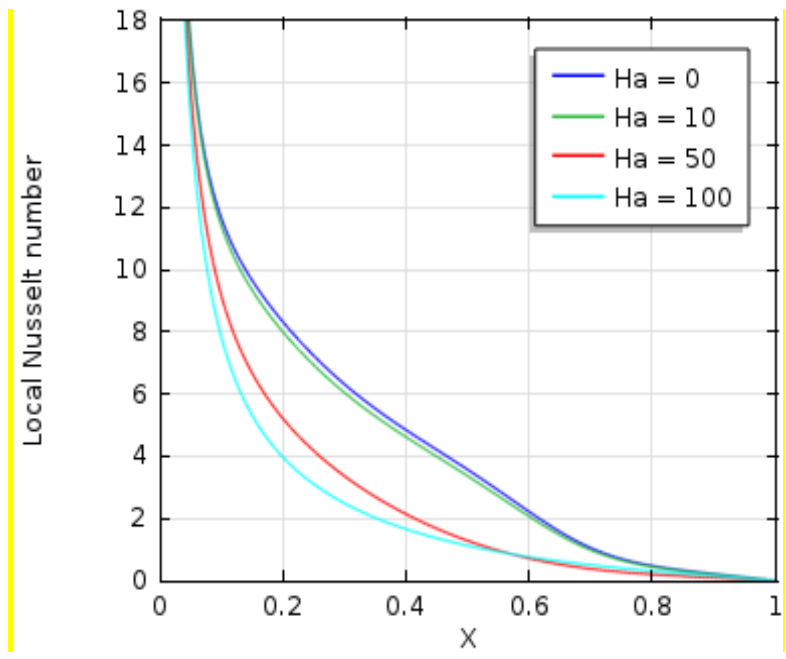

(b)

Fig 5: Local Nusselt number for (a) Rayleigh number, and (b) Hartmann number on horizontal heated wall.

Without external magnetic impact $(H a=0)$, the adjacent fluid near the horizontal heated wall takes heat and these heated particles moves upwards on account of buoyant force whilst comparatively refrigerant liquid neighbor cold wall access to horizontal warmed wall consequently a smooth large circulation cell is created entire the cavity. As $\mathrm{Ha}$ increases $(>0)$, the streamline patterns are changed and circulations power within the cavity decreases significantly. Because the external strong magnetic field generates Lorentz force inside the enclosure

UniversePG I www.universepg.com

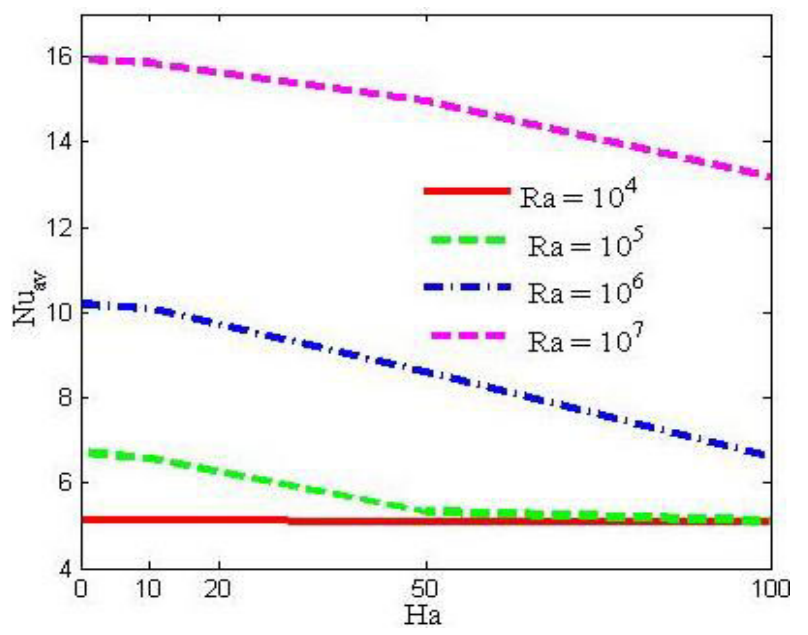

(a)

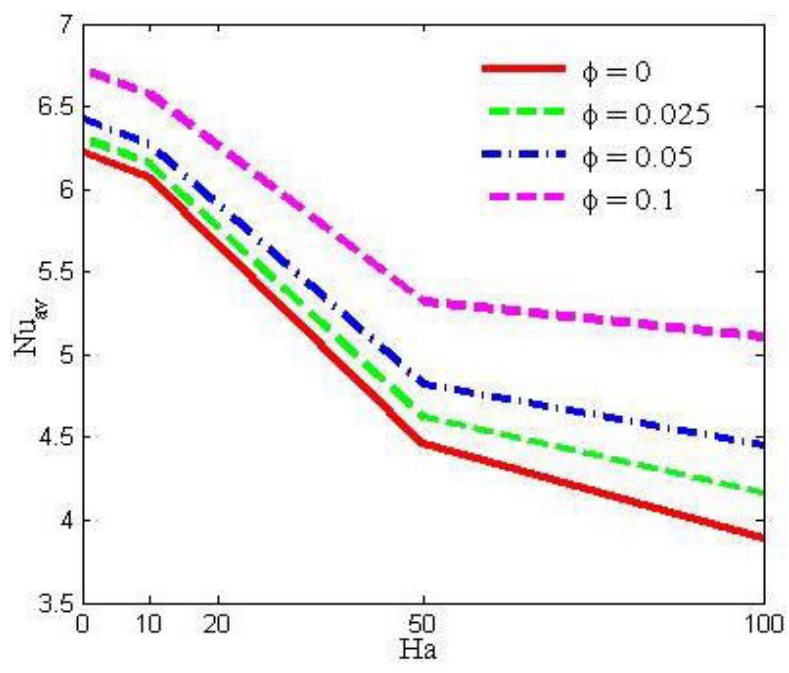

(b)

Fig 6: Average Nusselt number for (a) Rayleigh number, and (b) nanoparticles volume facrtion against Hartmann number.

that have a character of opposing of its propagation which weakens the streams within the enclosure.

Fig 4(b) demonstrate Hartmann number ( $H a=0,10,20,50)$ influence on isotherms for fixed $\phi=0.04$ and $R a=10^{5}$. These figures illustrate that the isotherms patter are more and more pronounced for the low Hartmann number $(H a=0)$ which indicates the strong convection happens for non-appearance of magnetic field. Isothermal strength decreases and less pronounce for increase of $\mathrm{Ha}$. Because potential Lorentz force is produced from Hartmann number which reduce the temperature distribution. 
Therefore, Magnetic field can be used for controlling the flow domain as well as temperature transfer rate within enclosure.

\section{Impact of Nusselt number:}

Fig 5 demonstrates influence of Local Nusselt number using (a) Rayleigh number ( $R a$ ) and (b) Hartmann number $(\mathrm{Ha})$ on horizontal heated wall. These figures represents, local Nusselt number increases for augmentation $R a$ and diminishes for the enhancement of $\mathrm{Ha}$. These figures also represents that average temperature transfer value remains constant for low $R a(=0)$ which indicates that conduction is the principal mode of temperature flow. Fig 6 depicts outcomes of $N u_{a v}$ of (a) Rayleigh number (Ra) against $H a$, and (b) nanoparticles volume fraction $(\phi)$ against $\mathrm{Ha}$ on horizontal warmed wall. These figure narrate that $N u_{a v}$ increases with the increase of both $R a$ and $\phi$

Whereas diminishes for augmentation of $\mathrm{Ha}$. The strong buoyancy force and external magnetic field change temperature transfer value significantly. Also, additional nanoparticles into the base fluid enhances remarkably temperature transfer value. This figures also show that the average rate of temperature flow remains constant for low $R a\left(=10^{4}\right)$.

\section{CONCLUSION:}

We have investigated numerically free convectional flow as well as temperature flow of a right-angled triangle charged by cupper-water nanofluid considering with the help of Galerkin weighted residual finite element analysis. The influence of various parameter are presented using streamline contours, isotherm contours, and Nusselt number and interpreted. The following main findings are listed:

i. Rayleigh number play significant roll on flow field and temperature transfer value.

ii. The fluid flow enhances for rising Rayleigh number whereas diminishes for rising Hartmann number. iii. Low Hartmann number and higher Rayleigh number conform better temperature transfer value.

iv. Additional nanoparticles significantly improves temperature flow.

v. Average Nusselt number augments for upper Rayleigh number whereas diminishes for rising Hartmann number.

\section{NOMENCLATURE}

$B_{0} \quad$ magnitude of magnetic field

$c_{p} \quad$ specific heat at constant pressure

$g \quad$ gravitational acceleration

$\mathrm{Ha}$ Hartmann number

$k \quad$ thermal conductivity

$L \quad$ length of the enclosure

$N_{a v} \quad$ average Nusselt number

$p \quad$ dimensional pressure

$P \quad$ dimensionless pressure

Pr Prandtl number

$\mathrm{Ra} \quad$ Rayleigh number

$T \quad$ fluid temperature

$u, v \quad$ velocity component

$U, V$ dimensionless velocity component

$x, y \quad$ coordinates

$X, Y \quad$ Dimension less horizontal coordinate

\section{Greek symbols}

$\alpha \quad$ thermal diffusivity

$\beta \quad$ thermal expansion coefficient

$\phi \quad$ solid volume fraction

$\mu \quad$ dynamic viscosity

$v \quad$ kinematic viscosity

$\theta \quad$ non-dimensional temperature

$\rho$ density

$\sigma \quad$ electric conductivity

$\psi \quad$ stream function

$\begin{array}{ll}\text { Subscript } & \\ h & \text { heat surface } \\ c & \text { cold surface } \\ n f & \text { nanofluid } \\ s & \text { nanoparticle } \\ b f & \text { Base fluid }\end{array}$




\section{ACKNOWLEDGEMENT:}

The author is very grateful to the editor and reviewers.

\section{CONFLICT OF INTERESTS:}

The authors declare no conflict of interest.

\section{REFERENCES:}

1. Abu-Nada, E., and Oztop H., (2009). Effects of inclination angle on natural convection in enclosures filled with $\mathrm{Cu}$-water nanofluid.

Int. J. Heat fluid Flow, 30, 669-678.

https://doi.org/10.1016/j.ijheatfluidflow.2009. $\underline{02.001}$

2. Arani A., Mahmoodi M., and Amini M., (2011). Free convection in a nanofluid filled square cavity with horizontal heated plate. Defect und Diffusion Forum, 312-315, 433438.

https://doi.org/10.4028/www.scientific.net/DD F.312-315.433

3. Aydin O., and Yesiloz G., (2011). Natural convection in a quadrantal cavity heated and cooled on adjacent walls. ASME J. Heat Transfer, 133(5), 1-7. https://doi.org/10.1115/1.4003044

4. Basak T., Roy S., Babu S.K., and Balakrishnan A.R, (2008). Finite element analysis of natural convection flow in an isosceles triangular enclosure due to uniform and non-uniform heating at the side walls. Int. J. Heat Mass Transfer, 51(17-18), 44964506.

https://doi.org/10.1016/j.ijheatmasstransfer .2007 .12 .018

5. Bhardwaj S., and Dalal A., (2013). Analysis of natural convection heat transfer and entropy generation inside right-angled triangular enclosure. Int. J. Heat Mass tran., 65, 500-513.

https://doi.org/10.1016/j.ijheatmasstransfer.20 $\underline{13.06 .020}$

6. Boulahia Z., Wakif A., and Sehaqui R., (2016). Numerical investigation of mixed convection heat transfer of nanofluid in a lid-driven square cavity with three triangular heating blocks.International Journal of Computer Applications, 143(6), 0975-8887. https://doi.org/10.5120/ijca2016910227

7. Choi S.U.S., and Eastman J.A. (1995). Enhan-cing thermal conductivity of fluids with nanoparticles. Int. Mech. Eng. Cong. and Expo, ASME, San Francisco, USA. 196515.

8. Ece M.C., and E. Buyuk, (2006). Natural convection flow under a magnetic field in an inclined rectangular enclosure heated and cooled on adjacent walls. Fluid Dynamics. Res., 38, 564-590. https://doi.org/10.1016/j.fluiddyn.2006.04.002

9. Ghasemi B., and Aminossadati S.M., (2009). Natural convection heat transfer in an inclined enclosure filled with a waterCuo nanofluid. Numer. Heat Transfer A, 55, 807-823. https://doi.org/10.1080/10407780902864623

10. Islam S, Islam MS, and Mandal S. (2020). One dimensional heat transfer through a uniform plane wall by using finite volume method, Aust. J. Eng. Innov. Technol., 2(2), 24-30. https://doi.org/10.34104/ajeit.020.024030

11. Kamiyo O.M., Angeli D., Barozzi G.S., Collins M.W., Olunloyo V.O.S., and Talabi S.O.A., (2010). Comprehensive review of natural convection in triangular enclosures. Applied Mech. Rev., 63, 060801-13. https://doi.org/10.1115/1.4004290

12. Manca O., Jaluria Y., and Poulikakos D. (2010). Heat transfer in nanofluids. Advances in Mech. Eng. Art. ID 380826, 2010, Pp. 1-2. https://doi.org/10.1155/2010/380826

13. Oztop H.F., and Abu-Nada E. (2008). Numerical study of natural convection in partially heated rectangular enclosures filled with nanofluids, Int. J. Heat F. Flow, 29, 1326-1336.

https://doi.org/10.1016/j.ijheatfluidflow.2008. $\underline{04.009}$

14. Rahman M.M., Alim M.A., and Mamun M.A.H., (2009). Finite element analysis of mixed convection in a rectangular cavity 
with a heat conducting horizontal circular cylinder. Nonlinear Anal. Model. Control, 14(2), 217-247.

https://www.journals.vu.lt/nonlinear-analys is/article/view/14522/13451

15. Rahman M.M., Alam M.S, Al-Salti N., and Eltayeb I.A. (2016). Hydromagnetic natural convective heat transfer flow in an isosceles triangular cavity filled with nanofluid using two component nonhomogeneous model. Int. J. of Thermal Sciences, 107, 272-288. https://doi.org/10.1016/j.ijthermalsci.2016.04. $\underline{009}$

16. Rashmi W., Ismail A.F., Khalid M., and FaridahY. (2011). CFD studies on natural convection heat transfer of $\mathrm{Al}_{2} \mathrm{O}_{3}$-water nanofluids. Heat Mass Transfer, 47, 13011310.

https://doi.org/10.1007/s00231-011-0792-x

17. Sheikholeslami M., Bandpy M.G., Ellahi R., and Zeeshan A. (2014). Simulation of MHD $\mathrm{CuO}$-water nanofluid flow and convective heat transfer considering Lorentz forces. $J$ Magn. Magn. Mater., 369, 69-80. https://doi.org/10.1016/j.jmmm.2014.06.017
18. Yesiloz G., and Aydin O. (2013). Laminar natural convection in right-angled triangular enclosures heated and cooled on adjacent walls. International Journal of Heat and Mass Transfer, 60, 365-374. https://doi.org/10.1016/j.ijheatmasstransfer.20 13.01 .009

19. Uddin M.J., and Hoque A.F., (2018). Convective heat transfer flow of nanofluid in an isosceles triangular shaped enclosure with an uneven bottom wall. Chemical Engineering Transactions, 66, 403-408. https://doi.org/10.3303/CET1866068

20. Varol Y., Oztop H.F., and Yilmaz T., (2007). Natural convection in triangular enclosures with protruding isothermal heater. Int. J. Heat Mass Transfer, 50(1314), 2451-2462. https://doi.org/10.1016/j.ijheatmasstransfer.20 06.12 .027

21. Zienkiewicz O.C., and Taylor R.L., (1991). The finite element method. $4^{\text {th }}$ ed. McGrawHill.

https://trove.nla.gov.au/versio n/40313901

Citation: Islam T., Akter N. and Jahan N. (2020). MHD free convective heat transfer in a triangular enclosure filled with Copper-water nanofluid, Int. J. Mat. Math. Sci., 2(2), 29-38. https://doi.org/10.34104/ijmms.020.029038 क) क 